\title{
$\beta$-Catenin and canonical Wnts control two separate pattern formation systems in Hydra: Insights from mathematical modelling
}

\author{
Moritz Mercker ${ }^{*}$, Tobias Lengfeld², Stefanie Höger ${ }^{2}$, Anja Tursch², Mark Lommel ${ }^{2}$, Thomas W \\ Holstein $^{2 *}$ Anna Marciniak-Czochra ${ }^{1}$ \\ ${ }^{1}$ Institute of Applied Mathematics (IAM), Heidelberg University, 69120 Heidelberg, Germany \\ 2 Department of Molecular Evolution and Genomics, Centre for Organismal Studies (COS), Heidelberg University, \\ 69120 Heidelberg, Germany \\ * Corresponding authors. E-mail: mmercker_bioscience@gmx.de and thomas.holstein@cos.uni-heidelberg.de
}

\begin{abstract}
Formation of the body axes and the subsequent formation of the apical termini are two fundamental steps during animal development. In Hydra, nuclear $\beta$-Catenin and canonical HyWnt3 were identified as major players active in both processes. Based on molecular knowledge of canonical Wnt signaling directly linking nuclear $\beta$-Catenin and HyWnt3 activity, it was frequently assumed that de novo axis formation and the head formation were part of the same pattern formation system. In this work, combining new model simulations with available experimental results, we demonstrate that nuclear $\beta$-Catenin and HyWnt3 most likely contribute to two separate de novo pattern formation systems in Hydra, organizing development and differentiation on two different spatial scales. In particular, our results suggest that the nuclear $\beta$-Catenin acts on the scale of the whole body, controlling axis formation, whereas canonical HyWnt3 signaling is involved in a downstream pathway responsible for small-scale patterning of the head. Consequently, also in other animals where axis formation was ascribed to canonical Wnt signaling, the underlying mechanisms may be more complex than previously assumed.
\end{abstract}

\section{Introduction}

Understanding the mechanisms responsible for formation of the primary body axis is among the crucial issues of developmental biology 75. In general, the process is based on maternally provided pre-patterns, such as in the fruit fly embryo [22]. In some cases, axis formation during embryogenesis can be a self-organized process, as it was demonstrated in various developmental systems ranging from simple metazoans to complex mammalian organs 31,73, 83,98 105. But even in vertebrate systems, recent data reveal that spontaneous symmetry breaking occurs if extra-embryonic tissue is absent 4, 96, 99. Consequently, self-organization may serve as a mechanism to ensure robustness of developed structures under various intrinsic and extrinsic conditions.

Cnidarians are a popular model system to study general and transmissible principles of development 25 43 50]. In particular, the freshwater polyp Hydra has been used to study development and regeneration for nearly 300 years. Hydra is a model organism allowing investigation of axis and head formation under different natural and perturbed conditions. In adult polyps, head and axis patterning are constitutively active to ensure maintenance of patterns in a continuous flow of self-renewing and differentiating cells $7,9,10$. Moreover, the system regenerates "extremities", such as the head or the foot, as it was discovered in 1740 by Abraham Trembley 95. and studied in a range of tissue manipulation experiments 869 . Notably, Hydra can also regenerate entire polyps from a bulk of dissociated and re-aggregated cells [31, which is a paradigm for de novo pattern formation 82, 93. Furthermore, Hydra tissue pieces can be transplanted from one polyp (donor) to another (host) by "grafting", thus providing a model for mutual spatial interactions of tissue pieces from different body regions, respectively from different morphogenetic backgrounds 20,56,57, 85, 110. Body axis and head formation also take place during budding, Hydra's asexual form of reproduction where buds evaginate and grow spontaneously in the budding region of the mother polyp, eventually detaching as functional polyps 74. Finally, as Hydra undergoes sexual reproduction, it allows studying mechanisms driving axis and head formation during embryogenesis as well [23, 29, 60]. 
One of the main questions in Hydra research is related to formation, regeneration and maintenance of the body axis including the head $24,33,89,102$. The mechanisms driving head and axis formation have been already addressed in early grafting and regeneration experiments that shed light on general underlying properties observed at the tissue level (e.g. 20, 31, 56, 57, 95 ). More recent studies discovered several molecular candidates involved in these processes. In particular, $\beta$-Catenin and HyWnt3 showed to be the key players of the head and axis formation in Hydra 18, 28, 40, 92. In parallel, the canonical Wnt signaling was intensively studied in a range of model organisms, demonstrating that activity of Wnt molecules linked to the translocation of $\beta$-Catenin into the nucleus are involved in control of various developmental processes (reviewed in [3, 49]). This frequently led to a conclusion that the canonical Wnt signaling pathway constituted the core-structure of the patterning system in Hydra. Consequently, assuming that HyWnt3 and $\beta$-Catenin were involved in the same pattern formation system, no distinction was usually made between mechanisms of body axis- and of the head pattern formation process, e.g., $43,61,77,101$.

In addition, Hydra attracted a lot of attention in theoretical pattern formation research, starting from the seminal paper of Allan Turing [97] who suggested that specific nonlinear interactions facilitated by different diffusivities can describe de novo formation of patterns that may be applied to reproduce cutting experiments in Hydra. The most famous realization of Turing's idea in a mathematical model of biological pattern formation is the activator-inhibitor model proposed by Alfred Gierer and Hans Meinhardt, 30, 32, 61, 63, 65]. This abstract model provided hints as to how complex intracellular pathways coupled to cell-to-cell communication through diffusive molecules may lead to symmetry breaking and emergence of spatially heterogeneous patterns of gene expression. The activator-inhibitor model and its extensions $6,11,55,59,67,84$ always assume that both, axis and head formation are driven by the same pattern formation mechanism 63 64]. Based on the molecular knowledge of canonical Wnt signaling, the hypothesis remained in agreement with several Hydra experiments demonstrating that both molecules, nuclear $\beta$-Catenin and Wnt3, exhibit spatio-temporal correlations. In particular, their ex-

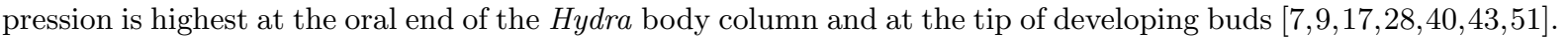
Furthermore, a pharmaceutical or transgenic induction of nuclear $\beta$-Catenin induces increases, at least transiently, the number of HyWnt3 spots $18,28,34,35$. There are also several studies on the transcript level showing that expression of HyWnt3 depends on $\beta$-Catenin 72, 77, 101.

In this work, we provide a systematic model-based analysis of experimental data, which suggests existence of two distinct pattern formation systems governing body axis and head formation. A systematic simulation study of a model integrating $\beta$-Catenin and HyWnt3 signaling into a single patterning mechanism identifies experiments that cannot be reproduced by such mechanism. Motivated by the discrepancy between model and experiments, we extend the model to describe dynamics of nuclear $\beta$-Catenin and HyWnt3 by two pattern formation systems connected via the canonical Wnt pathway. We show that $\beta$-Catenin translocation is involved in the largescale formation of the body axis, whereas canonical Wnt signaling (including HyWnt3) is a separate small-scale pattern formation system responsible for the organizer formation, eventually controlling small-scale head formation downstream of $\beta$-Catenin. Our results suggest that also in several other animals, where canonical Wnt signaling was assumed to drive body axis formation [75], the control mechanisms may be more complex, and the small scale pattern formation processes of the head vs. those of the large-scale body axis should not necessarily be identified with each other. In the current paper, we focus on the core structure of such model and provide its systematic justification based on a range of existing experimental results.

\section{Results and Discussion}

\section{Summary of experiments contrasting the function of $\beta$-Catenin and HyWnt3 in Hydra patterning}

\section{Regeneration and grafting experiments}

Several tissue level studies have already indicated that head and axis formation in Hydra are established by two different patterning systems acting on two different spatial scales. Although both, Hydra head and body column tissue, can lead to ectopic head and axis formation when grafted into a host polyp [7, 17, 110, only the apical part of the head (the hypostome) has the organizer capacity and transmits a signal inducing host tissue to form 
a secondary axis 17. Grafting a tissue of the body column does not stimulate the surrounding tissue but selforganizes into a secondary axis solely composed of the transplanted tissue $7,17,19,20$. Furthermore, the tissue from the apical tip appears to induce the secondary axis at much higher frequency [45] compared to grafted other parts of the body (e.g., 56 57]). Moreover, it was shown that even smaller pieces than the hypostome, i.e. clumps of 10 epithelial cells derived from the regenerating hypostome can induce a head axis in reaggregates 92. All these observations suggest that processes of axis and head formation originating from the apical tip (small-scale structure) vs. tissue of the body column (large-scale structure) must involve different signaling factors 17,57 .

\section{The developmental viewpoint}

Discrimination between two patterning systems acting on two different scales to control robust formation of the Hydra body plan is also compelling from the developmental point of view. First, existence of de novo pattern formation on the scale of the body axis is indicated by the self-organization process during regeneration in $H y d r a$ aggregates. The resulting body-axis gradient fits to the experimental observation that transplantation of the tissue pieces from the head region has a higher probability to induce a secondary axis than grafts from more basal regions. Presence of such 'head activation gradient' was experimentally confirmed several times [57]. This was also referred to as the 'head inducing potency' [33], gradient of 'head formation capacity' 17], '-competence' 92], '-potential' 38, '-positional value' 2, 109, or the 'source density' 32,63.

Second, the head activation gradient has to be subsequently translated into the fine-scaled patterning in the Hydra head region. Regeneration experiments indicate that the location of head vs. foot formation does not depend on absolute but rather on relative levels of the head activation gradient 8.96 . Hence, a 'direct' translation of the gradient into fine-scale patterns, for example based on a threshold mechanisms as originally proposed by Lewis Wolpert 108,109, is unlikely, since such a mechanism would need to measure very small concentration differences between adjacent cells 62 .

By contrast, Hydra appears to follow a different strategy to realize the transition from large- to small scale patterns: the head activation gradient (co-localizing with nuclear $\beta$-Catenin/Tcf expression) yields a small organizing spot ('head organizer') that is defined by HyWnt3 expression [7, 10, 18, 40, The latter is localized at maximal (or sufficiently high) levels of nuclear $\beta$-Catenin/Tcf [40,92]. The organizer spot is assumed to control the stepwise construction of the Hydra head including tentacles [8, 10, 13, 17, 51. However, we want to point out that the relationship between the large-scale body-axis system and the small-scale organizer system is most probably bidirectional - as indicated by grafting experiments [17] and studies of Hydra aggregates [40, 92. In particular, it is assumed that the local expression of head/organizer specific "point source genes" (such as HyWnt3 or $\mathrm{HyBra}$ ) direct/restrict the large-scale expression patterns e.g. of $\beta$-Catenin/Tcf 92 .

In summary, instead of the possibly non-robust direct transformation of the large-scale gradient into small-scale patterns, the large-scale body axis gradient seems to interplay in a mutual positive feedback with another, smallscale patterning system defining the head organizer. Thus, robustness is achieved through redundant mechanisms (acting however on different scales) which is a well-known principle in various biological contexts [103].

\section{Single-gene expression studies}

In situ hybridization- and GFP-based reporter gene studies reveal that $\beta$-Catenin and HyWnt3, although colocalizing with respect to their maxima, are expressed on different spatial scales: $\beta$-Catenin (and the associated Tcf) show diffusive/cloudy expression patterns matching the scale of the body axis, whereas HyWnt3 expression and that of all other Hydra Wnt genes always occur in tiny spots [18, 28, 40, 44, 51, 91, 92. Activity of the two factors differs not only in the localization of spatial patterns, but also in their dynamics. Except for the experiments involving tissue injury that may trigger HyWnt3 expression directly 102], there is evidence that HyWnt3 expression appears at later stages than $\beta$-Catenin/Tcf activity. A distinct delay in the expression of HyWnt3 compared to $\beta$-catenin/Tcf is observed during embryogenesis 23] as well as during budding, where HyWnt3 expression coincides with the first bud protrusions [40] while $\beta$-Catenin/Tcf expression appears already prior to the first visible deformations [44, 104]. Indeed, inhibition of $\beta$-Catenin prevents bud formation including the expression of several bud- and organizer specific genes 104]. In summary, these spatial and temporal expression 
studies suggest that activity of both molecules is controlled by different mechanisms that are acting on different spatio-temporal scales, where Tcf/ $\beta$-Catenin frequently appears to precede HyWnt3 signaling.

\section{Transcriptomic analyses and signaling pathways}

Recent progress in the understanding of the canonical Wnt signaling in different animals provides a direct link between Wnt-molecules, nuclear $\beta$-Catenin, and Tcf-signaling 3,49,72. This finding has led to the widespread assumption that $\beta$-Catenin/Tcf and HyWnt3 must play within the same pattern formation system with canonical Wnt signaling being at the core of this system 104. However, the observation that expression of HyWnt3 requires nuclear $\beta$-catenin/Tcf does not imply that the body-scale pattern formation system coordinated by $\beta$-catenin/Tcf relies on HyWnt3. On the contrary, while HyWnt3 function is associated with the head organizer 7, 10, 18, 40, $\beta$ catenin/Tcf-dependent signaling is involved in diverse molecular, non-molecular, intrinsic and extrinsic processes. Thus, its role is versatile and fundamental: It is required for the early regeneration response and pre-patterning [36], and controls the expression of approximately 1000 different genes, including several components of BMP, Notch and TGF $\beta$ pathways, several TFs, as well as genes influencing cell-cell adhesion, cytoskeletal components, and the ECM 77, 104. Of specific significance for Hydra axis formation is the nodal-pitx cassette that has been shown to act under control of $\beta$-Catenin [104]. Moreover, $\beta$-Catenin appears to be a required co-factor to establish a biradial budding asymmetry 104. Additionally to its role as an important transcriptional co-factor in cell nuclei, the membrane-associated distribution of $\beta$-Catenin in other body regions indicates its function in Hydra tissue mechanics 21, 40, 41, 44], such as in cell-cell adhesions [71]. Furthermore, $\beta$-Catenin expression levels have been recently linked to ECM elasticity [100, which in turn plays an important chemical and mechanical role during pattern formation and regeneration. It has been also recently shown that even external biotic or abiotic environmental cues affect $\beta$-Catenin mediated signaling and pattern formation 12,90 . In the light of the complexity of $\beta$-catenin/Tcf-related processes, it is rather likely that $\beta$-catenin-dependent HyWnt3 expression is only one of several pattern formation loops activated by gene expression downstream of $\beta$-catenin/Tcf [72, 104, thus making HyWnt3 expression dispensable for body axis formation.

\section{Molecular manipulations and multi-headed phenotypes}

Molecular-biological techniques allow analyzing Hydra phenotypes resulting from a body-wide overexpression or knockdown of single genes [54 107]. In particular, $\beta$-catenin knockdown 101] and overexpression [28] have been studied in Hydra lines. Currently, also HyWnt3 overexpression lines are available [112, and knockdowns of the putative HyWnt3 inhibitors have been recently presented. Inhibitors can act directly on the level of transcriptional regulation or by interference with Wnt-ligands, such as the Wnt antagonist Dickkopf (Dkk 1/2/4) 2 35], Sp5 [101] and HAS-7 112. As expected, overexpression (direct or indirect resulting from inhibition of an inhibitor) of either $\beta$-catenin or HyWnt3 lead to phenotypes with multiple heads (c.f., Fig. 1 e-k). However, a more detailed look at these phenotypes allows the distinction of two different categories. If HyWnt3 is permanently increased (either directly through overexpression 112], or indirectly by Sp5- 101] or HAS-7-knockdown [112]), the resulting animals frequently show multiple heads, which are located in a close vicinity to each other ('bouquet phenotype' - Fig. 1 $\mathrm{h}-\mathrm{k}$ ). In Sp5-knockdown animals these ectopic heads/axes particularly occur at the oral pole or in the budding zone where $\beta$-catenin/Tcf levels are high 101. The same holds for HyWnt3 overexpressing animals, however, ectopic head locations are more variable here. In contrast, a permanent increase of $\beta$-catenin results in a phenotype with regular branches of new axes, with a natural distance between head and budding zone ('branched phenotype' - Fig. 1 e-g). Consequently, even the phenotypes resulting from overexpression experiments and observations on the tissue-level indicate that HyWnt3- and $\beta$-catenin/Tcf signaling mediate different aspects of Hydra patterning. 
transient (initial) increase of beta-Catenin

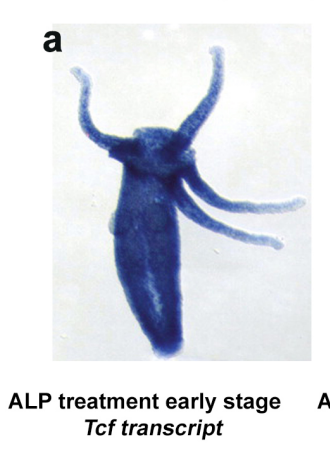

b

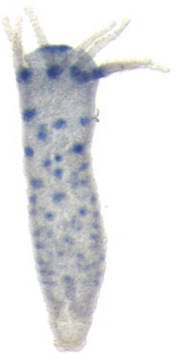

ALP treatment early stage HyWnt3 transcript

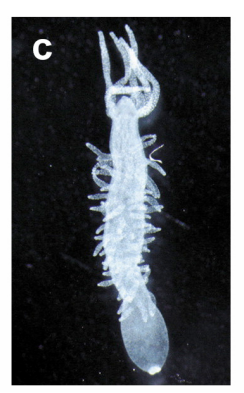

ALP treatment late stage phenotype

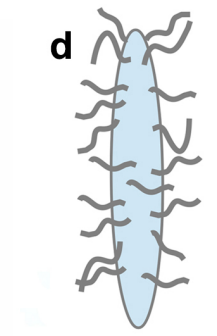

"tentacle phenotype“

\section{permanent increase of beta-Catenin}

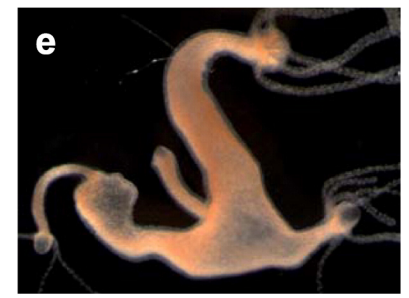

beta-Catenin overexpression phenotype

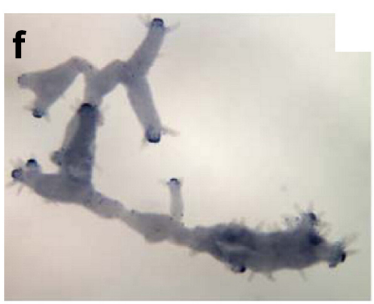

beta-Catenin overexpression HyWnt3 transcript

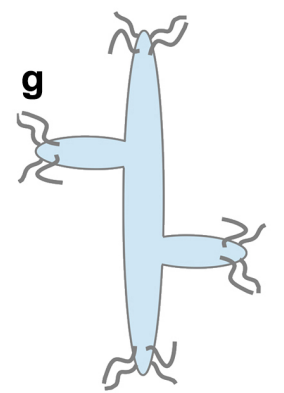

„branched phenotype“

permanent increase of HyWnt3

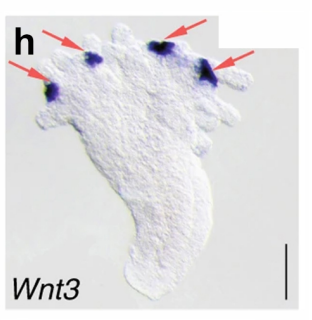

head regeneration with Sp5-knockdown HyWnt3 transcript

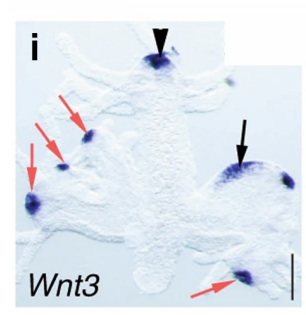

budding with Sp5-knockdown HyWnt3 transcript

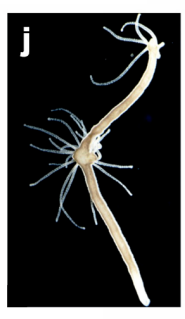

HyWnt3 overexpression
phenotype

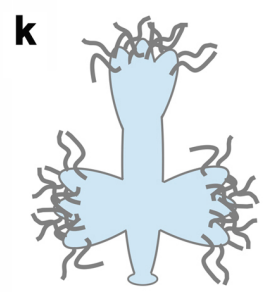

„bouquet phenotype“

Figure 1. Experimental data $(\mathrm{a}-\mathrm{c}, \mathrm{e}-\mathrm{f}, \mathrm{h}-\mathrm{j})$ and sketches of phenotypes $(\mathrm{d}, \mathrm{g}, \mathrm{k})$ resulting from a transient increase of $\beta$-catenin/Tcf $(\mathrm{a}-\mathrm{d})$, a permanent increase of $\beta$-catenin/Tcf $(\mathrm{e}-\mathrm{g})$ and a permanent increase of HyWnt3 (h-k). Pictures a-c are modified from Ref. [18], e-f from Ref. 28], and h-i from Ref. 101. (the latter published under the Creative Common license). 
Interestingly, a non-permanent increase of $\beta$-catenin/Tcf using a high dose of the drug Alsterpaullone (ALP) does not lead to the formation of multiple axes. Instead, it yields in a transient expression of multiple HyWnt3 spots all over the body, followed by the formation of ectopic tentacles 18, 28 (Fig. 1 a $\mathrm{a}-\mathrm{d}$ ). If such an ALP treatment is combined with a Wnt3-knockdown, the number of ectopic tentacles is reduced demonstrating that $\beta$-catenin is sufficient to induce these in a HyWnt3 interdependent process [53. Finally, a lower dose of ALP applied for a longer time leads again to ectopic axes - comparable to the above described $\beta$-catenin overexpression phenotype.

\section{Computational approach to investigate the function of $\beta$-Catenin vs. HyWnt3}

\section{Mathematical setting}

To obtain mechanistic insights into the role of different signaling components of the Hydra patterning system, we propose a mathematical model describing their dynamics. The model is given in terms of partial differential equations (PDEs) that account for spatio-temporal interactions of signaling factors defined on an evolving domain representing the tissue. Application of the continuous modeling approach is justified by the large number of cells $\left(\geq 5 \times 10^{4}\right)$ in the system 80 . To account for a realistic geometry of the Hydra tissue bilayer, we adopt a mechanochemical modeling approach proposed in Ref. 66 68. We assumed that reaction-diffusion equations describing the signaling system are defined on a curved 2-dimensional surface that is embedded in a 3-dimensional space. The geometry of the curved surface evolves in time following a gradient-flow of a Helfrich-type energy reflecting the property that bending of the tissue away from a preferred local curvature is energetically unfavorable. We assumed that small tissue deformations, as for example in the initial phase of tentacle development, follow from patterns in gene expression. In contrast to the fully coupled mechano-chemical model of 67], the current model does not consider any feedback from mechanical properties of the tissue to the gene expression processes. Consequently, the pattern formation process is based solely on molecular interactions. The choice of model geometry is motivated by a realistic description of the tissue given by a radial-symmetric ellipsoid that undergoes small deformations due to the gene expression patterns.

Details of the mathematical setting are provided in 'Material and Methods' section. In the remainder of this section, we focus on the mathematical modeling of Hydra signaling, biological justification of the model structure and model validation based on experimental data.

\section{Mathematical model to test the hypothesis that $\beta$-Catenin and HyWnt3 control two sepa- rate pattern formation systems}

The simplest explanation of the spatio-temporal differences between the localized $H y W n t 3$ expression and body column-scale $\beta$-catenin/Tcf patterns could be provided by a mechanism in which $\beta$-catenin/Tcf is a part of a signaling loop exhibiting de novo formation of a pattern with HyWnt3 expression being activated above a certain $\beta$-catenin/Tcf threshold, as proposed in Ref. 63. Such threshold-mechanism would result in HyWnt3 expression at the spots determined by the local maxima of the $\beta$-catenin/Tcf pattern, where the critical threshold is exceeded. However, there exist several experimental observations suggesting that HyWnt3 drives a partially autonomous pattern formation system rather than being just a read-out of the $\beta$-catenin/Tcf activity.

An important hint about the complexity of the system is provided by pharmaceutical manipulations based on Alsterpaullone (ALP) treatment. As ALP prevents $\beta$-catenin degradation, the experiment results in a high and body-wide constant level of $\beta$-catenin/Tcf, see Fig. 11 a. Interestingly, this pattern is not followed by HyWnt3,of whose expression exhibits a complex structure of multiple organizer-sized spots all over the body, see Fig. 1 $\mathrm{b}$ and Ref. 18, 28, 34, 35, 40, 101]. This confirms that an increased activity of $\beta$-catenin/Tcf yields an increased production of HyWnt3, but likewise demonstrates that its spatial dynamics must undergo an additional regulation mechanism. The latter leads to qualitatively different expression patterns of the two factors, which act on distinct spatial scales. In particular, we can see that even a broad domain of $\beta$-catenin/Tcf activity results in HyWnt3 patterns that are strictly localized (preserve the size) and hence may provide a precise instruction for the process of head formation. In contrast, the threshold-mechanism suggested by Wolpert would result in a size increase of HyWnt3 spots leading to a body-wide constant HyWnt3 expression in case of a strongly elevated $\beta$-catenin/Tcf level. By contrast, the observation of restricted HyWnt3 spots indicates the existence of a mechanism providing 
certain robustness of the organizer formation. In particular, it prevents increase of the HyWnt3 expression domain what seems to be important for the proper head organizer function. Thus, it seems to be unlikely that the head organizer formation solely depends on $\beta$-catenin/Tcf activity considering the variety of extrinsic and intrinsic

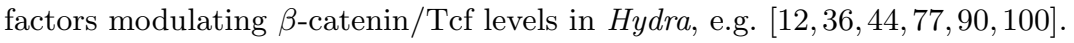

Motivated by the above considerations, we formulate a new mathematical model of symmetry breaking and pattern formation in Hydra, which allows reproducing the particular dynamics of $\beta$-catenin/Tcf and HyWnt3 activity. Our aim is to test if the existence of additional control of HyWnt3 patterns is sufficient to explain the experimental observations and to provide a core model of Hydra development and regeneration that can be later extended and applied to address new experimental questions. The proposed model is an extension of the wellestablished Gierer-Meinhardt model. It accounts for three subsystems describing (1) a pattern formation system of the body axis gradient, (2) a separate pattern formation system for the tentacles, and (3) a long-term storage of the body axis gradient (head forming potential / source density). We zoom out the head/body axis patterning system and explicitly distinguish between two (interconnected) pattern formation systems acting differently in the apical region versus the body column. We assume that a body-scale pattern formation system is informed by the nuclear $\beta$-catenin/Tcf that, among others, activates production of HyWnt3. The latter activity is supposed to be additionally mediated by an independent control loop that provides the head organizer function on a small-scale. A scheme of the model is presented in Fig. 2. Specific interactions between model components, assumptions on model parameters, initial conditions, and information about simulation code and software are given in 'Material and Methods' section.

The core-structure of the $\beta$-catenin/Tcf and HyWnt3 patterning systems is based on the activator-inhibitor signaling loop exhibiting Turing instability. For simplicity, we assume that HyWnt3 is a part of a signaling loop with a hypothetical Wnt3 inhibitor. The latter can be linked to the recently discovered Sp5 transcription factor that plays an important role in the transcriptional inhibition of Wnt3 [101]. It should be also pointed out the antagonistic interactions may occur on different levels. In addition to Sp5, we identified other well established Wnt antagonists that exhibit an synexpression with the putative gradient-like Wnt action domains. One is Naked Cuticle (Nkd) which binds to the Dishevelled (Dvl) family of proteins preventing the translocation of $\beta$-catenin into the nucleus 79, 106 and another is Notum, a Palmitoleoyl-Protein Carboxylesterase that requires glypicans to suppress Wnt signaling by depalmitoleoylation of Wnt proteins 46 47]. Furthermore, this complex network of Wnt antagonists might even include Wnt inhibitors that act by cleaving the Wnts to inactivate specific Wnt ligands 111,112. It is striking that some of them, like Nkd were shown in insects and mammals to have both negative and positive regulatory effects on Wnt signaling and exert a feedback control in a context dependent manner 27. Accounting for molecular details would then lead to a significant increase of model complexity, which is beyond the scope of this paper. Consequently, the proposed model does not account for molecular details of HyWnt3 interactions. The applied activator-inhibitor framework may be rather seen as an approximation of the de novo pattern formation mechanism that is still not understood on the molecular level. In this context it is worth mentioning that the desired dynamics may emerge not only from chemical processes (such as the activator-inhibitor coupling) but also from mechano-chemical, cellular and bio-electrical processes $\begin{array}{llllll}14 & 52 & 67 & 81 & 88\end{array}$.

\section{Model simulations and comparison to experimental data}

We simulated the model of a steady state system and a system challenged by ALP-treatment, knockdown or overexpression experiments. The aim of this work was to identify a minimal set of model components involving HyWnt3 and $\beta$-catenin/Tcf that allow an explanation of the observed patterns. In particular, we demonstrate the requirement of a supplementary regulation mechanism of HyWnt3, as one pattern formation system alone (as in the Gierer-Meinhardt models) is not sufficient to explain the experimental outcome of different manipulation of the $\beta$-catenin/Tcf and the HyWnt3 system. In the following, we discuss model results and limitations in the context of different experimental scenarios. 

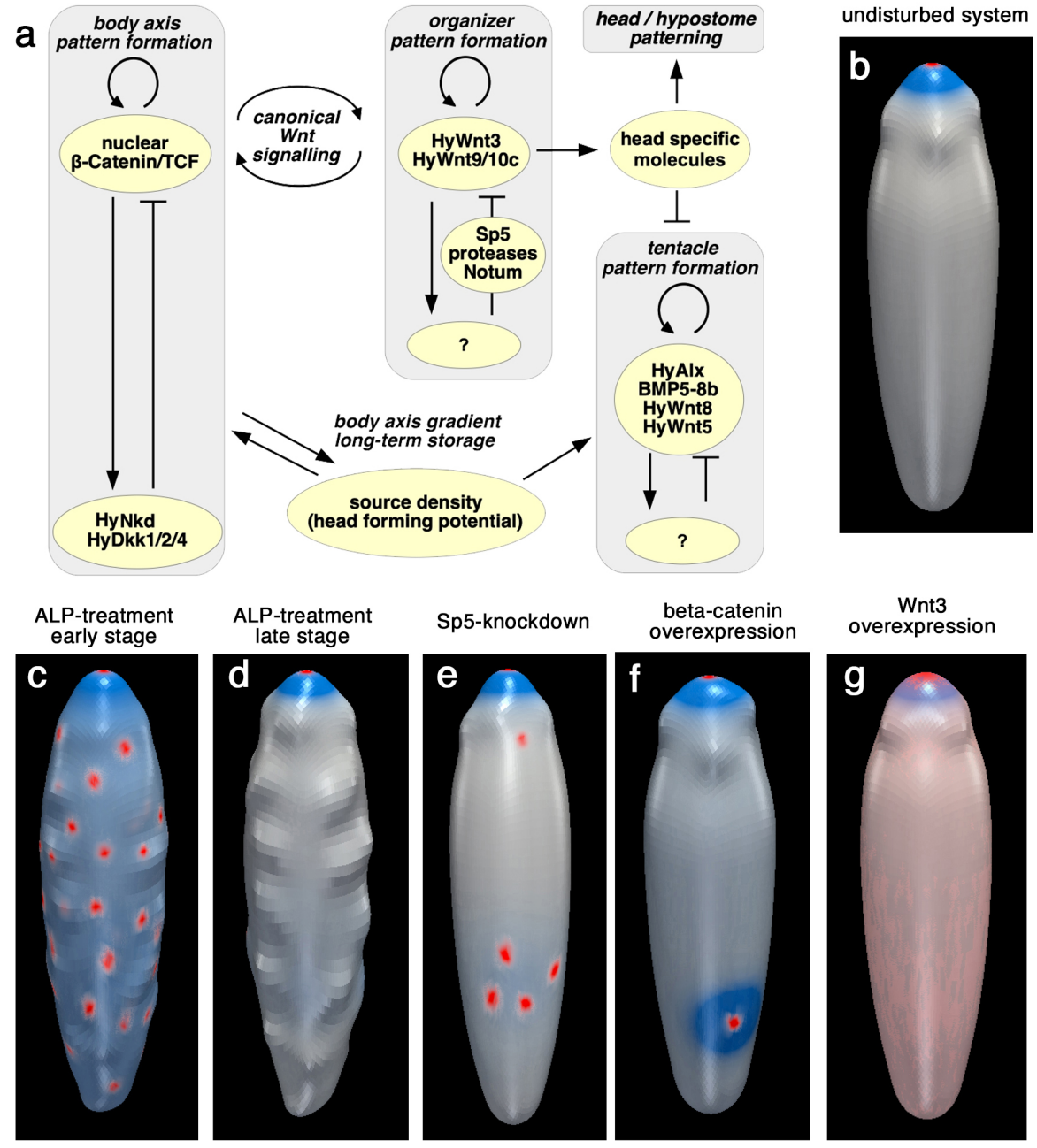

head regeneration HyAlx expression
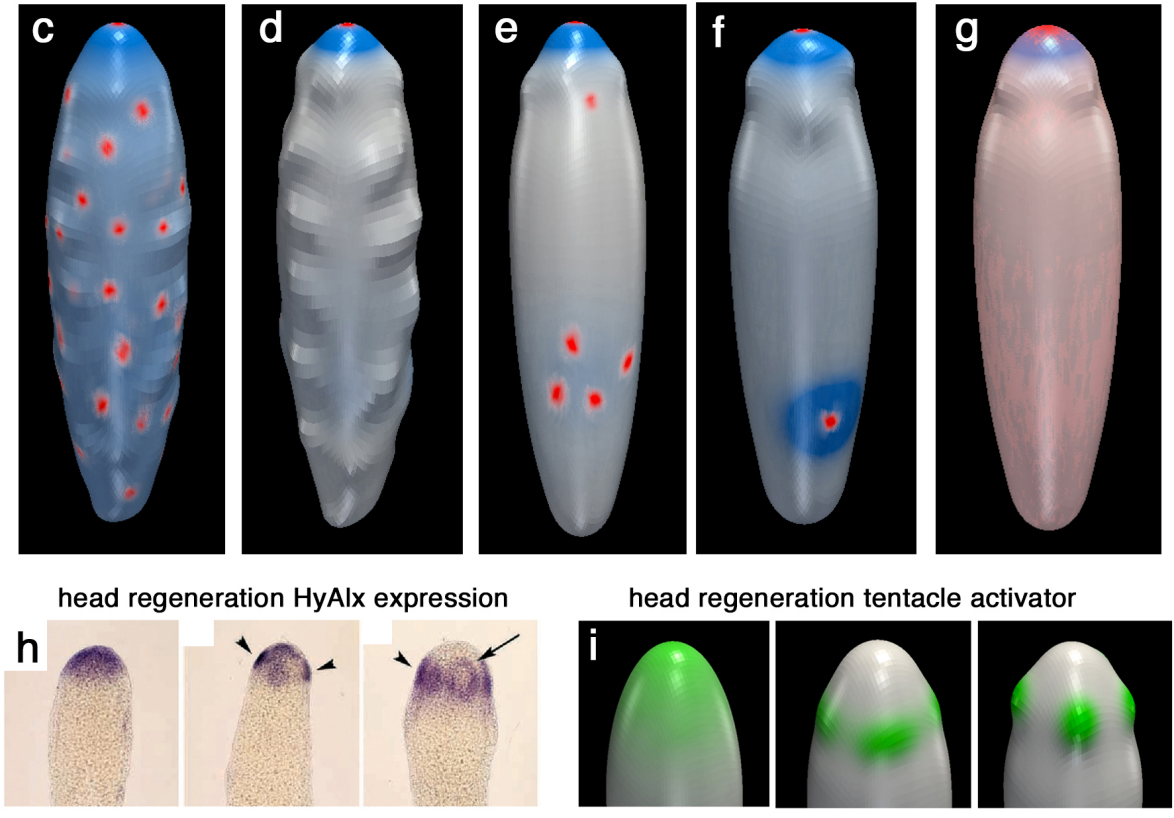

Figure 2. Scheme (a) and simulation results (b-g, i) of the new Hydra pattern formation model assuming separate pattern formation systems for the body axis (including $\beta$-catenin/Tcf [28, 40]), the head organizer (including HyWnt3 and HyWnt9/10c [76]), and the tentacle system (including HyWnt5, HyWnt8, HyAlx and BMP5-8b $76,78,86]$ ). In b-g, red color indicates high local levels of

HyWnt3/HyWnt9/10c and blue color high local levels of $\beta$-catenin/Tcf. Color-scaling is similar in all simulation snapshots. Developing tentacles are indicated by local tissue evaginations. The lower panel presents time series of experimentally observed HyAlx expression during head regeneration (violet color in (h) - figure adapted from Ref. 86]) and the tentacle activator marker during simulations (green colour in (i)). 
First, we checked that the model describes well the steady state scenario. Simulations (Fig. 2 b) show a spontaneous development of the head. The resulting gradient-like patterns of $\beta$-catenin/Tcf expression, with a maximum at the head, a tiny and sharp Wnt3 expression spot at the tip of the hypostome and a ring of tentacles beneath the head, stay in agreement with experimental observations 40. Also dynamics of the appearance of tentacle related patterns resemble previous experimental observations, compare Fig. 2 h and Fig. 2 i.

As previously discussed, these aspects of wild-type evolution are also captured by former models considering only one single pattern formation system for body-axis and head formation 63. 86. Hence, we focused on the ALP-treatment experiments for further model validation. Simulations of the model with initial conditions corresponding to ALP-treatment reproduce the experimentally observed patterns described e.g. in [18, 28], see Fig. 1 a-c. In early stages after the application of ALP, we observe an increase of $\beta$-catenin/Tcf level in the entire body column accompanied by multiple HyWnt3 spots (Fig. 2 c). At later stages, $\beta$-catenin/Tcf and HyWnt3 patterns resemble those of the steady state system, but ectopic tentacles develop at the body column (Fig. 2 d). Furthermore, simulations of a knockdown of the HyWnt3 inhibitor lead to multiple HyWnt3 spots in both, the head-region as well as in the budding zone (Fig. 2 e), which harmonizes with observations of adult polyps and head regenerates upon Sp5 knockdown (Ref. 101], c.f. Fig. 11 h-i). Interestingly, at late stages of these simulations, ectopic HyWnt3 spots vanish (not shown) whereas in real experimental systems they develop into ectopic heads 101. Nevertheless, the ectopic HyWnt3 spots stay significantly longer in the simulated model of Sp5-knockdown compared to simulations obtained upon ALP-treatment. Having said this, we conclude that in a real system a certain morphogen expression time is required but also sufficient to initiate a local cell-differentiation process. The latter leads to a 'fixation' of the organizer in place and demonstrates that a transient expression pattern is sufficient to control the process. Such effects are not incorporated in our presented and previous models. Finally, we compared the model to experiments based on $\beta$-catenin overexpression [28]. The model correctly predicts formation of one or multiple ectopic body axes having a much larger distance from each other compared to the Sp5-knockdown phenotype, see Fig. 1 e-f.

The only disagreement between the model and experimental observations is obtained when a scenario of HyWnt3 overexpression is simulated. Simulations of the corresponding model with an additional constant Wnt3 production results in a body-wide increase of HyWnt3 combined with a larger HyWnt3 spot at the upper hypostome (Fig. 2 g). In contrast, experiments show the development of multiple heads at varying positions (Fig. 1 j). This qualitative difference between model simulations and the experiment can be linked to the properties of the activator-inhibitor model that is behind the de novo pattern formation mechanism of our model. However, it can be mathematically shown for a general class of reaction-diffusion pattern formation systems (including the activator-inhibitor model) that an uniform increase of the activator production cannot change the shape of the pattern. Thus, the multi-head phenotype resulting form the HyWnt3 overexpression experiment cannot be explained by such models and a more refined model is needed.

\section{Summary and Outlook}

In this study, guided by a systematic analysis of available experimental data, we proposed a new mathematical model of head and body axis formation in Hydra. We integrated results of diverse experimental approaches and data sets including regeneration and grafting experiments, molecular/chemical manipulations leading to multiheaded phenotypes, analysis of single-gene expression patterns, and transcriptomic data related to the $\beta$-catenin and Wnt signaling pathway. We observed that in Hydra $\beta$-catenin/Tcf and HyWnt3 act qualitatively different in distinct/various spatial, temporal, and experimental contexts, which led us to the hypothesis that they require independent control mechanisms. We proposed a mechanism in which the core system controlling formation of the body-axis gradient is based on $\beta$-catenin/Tcf, while HyWnt3 is involved in an extra pattern formation system acting on a small spatial-scale in order to locate and define the head organizer. Both systems are tightly coupled through canonical Wnt signaling.

To test the performance of the proposed two-scale HyWnt3/ $\beta$-catenin patterning mechanism, we implemented these systems in a mathematical framework of reaction-diffusion equations. The model is based on an extension of the seminal Gierer-Meinhardt model (e.g., 61, 63]), in which the de novo patterning mechanism is provided 

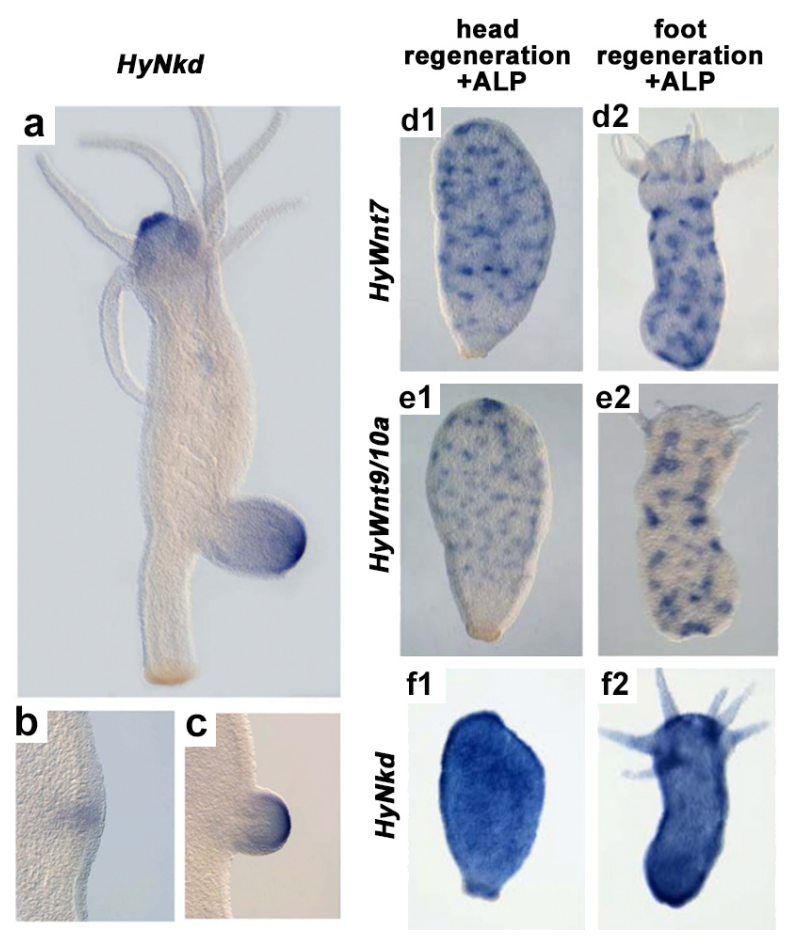

Figure 3. Experimental comparison of large-scale diffusive expression patterns and small-scale spotty expression patterns of different genes suggesting their involvement in the two different patterning systems: $(\mathrm{a}-\mathrm{c})$ Analysis of large-scale expression patterns of HyNkd in adult polyps, which suggests HyNkd to be involved in the large-scale $\beta$-catenin-based patterning system; $(\mathrm{d}-\mathrm{f})$ Formation of distinct patterns (diffusive vs. spotty) in animals treated with $5 \mu M$ ALP, evaluated after 72 h. It suggests that expression of multiple Wnts (d1,d2,e1,e2) is differently regulated than HyNkd (f1,d2).

by a Turing-type activator-inhibitor loop. In contrast to the previous models, we explicitly distinguish between the system defining large-scale formation of the body axis defined by a gradient of $\beta$-catenin/Tcf activity and the mechanism of head formation localized by HyWnt3. To account for a realistic geometry of the Hydra tissue bilayer, we adopted a mechano-chemical modeling approach coupling the morphogen dynamics with the evolution of a deforming tissue. Model simulations demonstrate the ability of the proposed model to explain a range of experimental observations that could not be described by a classical single activator-inhibitor loop. The model results are consistent with transient and stable HyWnt3 expression patterns upon ALP treatment, Sp5-knockdown, and $\beta$-catenin overexpression experiments.

The only disagreement between simulations and experiments is related to the HyWnt3 overexpression experiment showing a transition from a gradient-like pattern to a multiple-spot (ectopic heads/axes) structure 112, while model simulations predict a homogeneous body-wide increase in HyWnt3. Moreover, it was demonstrated that such dynamics cannot be obtained in a general activator-inhibitor model by an increase of activator production, which highlights the limitations of the activator-inhibitor mechanism. Mathematical understanding of this disagreement is an important step towards identification of a more plausible pattern formation mechanism. Further extensions of the model require more careful experimental investigations of the molecular interactions, accounting for Sp5 101], Wnt proteases 112 or other Wnt antagonists.

Our conclusions on co-existence of the two different regulatory mechanisms controlling body column and head 
formation are also supported by experiments showing co-existence of distinct types of patterns exhibited by different genes under the same treatment, see Fig. 3 The Figure provides an experimental setting for allocation of molecular candidates to either the large-scale body axis or the small-scale organizer in Hydra. Specifically, it links patterns exhibited by the putative Wnt/ $\beta$-Catenin inhibitor Naked Cuticle to those observed for $\beta$ Catenin/Tcf 36, 40, 44, which suggests that this molecule is rather involved in the body-axis gradient system. $H y N k d$ expression during budding $(\mathrm{Fig} 3 \mathrm{~b}-\mathrm{c})$ further reveals that this gene is already expressed during early stages of budding and regeneration, indicating a role during the basic pattern formation process. Analysis of expression patterns after ALP treatment confirms these assumption, since $H y N k d$ expression (f1-f2) shows a homogeneous body-wide pattern, similar to the expression pattern of $\beta$-Catenin/Tcf 18, 28, but significantly distinct from the spotty small-scale patterns of multiple Wnts $(\mathrm{d} 1, \mathrm{~d} 2, \mathrm{e} 1, \mathrm{e} 2)$. Indeed, it has been demonstrated that Naked/NKD is a widely conserved feedback regulator preventing the translocation of $\beta$-Catenin into the nucleus (by interacting with Dishevelled and Axin) 27, 106 and thus primarily affects $\beta$-Catenin signaling, whereas Wnt signaling is only affected indirectly.

Interestingly, recent experimental research indicated that beyond diffusing chemicals, physical cues such as discrete cellular nearest-neighbor interactions $13,26,48,70,87$, , tissue mechanics $14,52,67,88$, and bio-electrical processes [15], are actively contributing to pattern formation in Hydra. Thus, integration of non-diffusive and diffusive signals offers a viable alternative to the classical Turing theory of de novo pattern formation and may have important consequences for experimental studies.

In summary, the molecular basis of canonical Wnt signaling established during last decades 3 . 42 clearly indicates that Wnt signaling pathway plays an outstanding role during head and axis development not only in Hydra 40 but also in other higher organisms 75. In the context of canonical Wnt signaling, previous models did not distinguish between body axis and head formation. Thus, the combination of mathematical modeling and simulation with available experimental data enables us to provide first evidence that these two systems are given by two separate self-organizing processes. These two systems are coupled through the canonical Wnt signaling pathway, which ensures the continuous alignment of the head with the body axis.

Although accounting explicitly for HyWnt3 and $\beta$-catenin/Tcf, the proposed model involves hypothetical inhibitors that might be linked to the Sp5 transcription factor 101] or HyDkk1/2/4 22 35. Since refinement of the model to account for molecular details of the underlying mechanisms would lead to a significant increase of the model complexity, we formulate the basic HyWnt3/ $\beta$-catenin model in terms of a reduced mathematical representation of the underlying mechanisms. Moreover, numerous studies of different pattern formation mechanisms demonstrate the difficulty of distinguishing among them on the level of basic experimental data, thus showing the need of more detailed molecular information to select the plausible mechanism. The proposed mathematical model provides a tool to guide the respective experimental research and interpret its results.

In 2012, based on over 40 years of research into Hydra pattern formation, Alfred Gierer remarked that even detailed knowledge of the molecules involved in Hydra pattern formation would not be sufficient to explain the resulting spatial structures 30. We posit that the patterns arise as an emergent effect that can be understood from an interdisciplinary perspective, integrating different chemical and physical processes and principles at molecular, cellular, and tissue scales 14,30 . Further refinement of our models by integrating results from different biological, biophysical and biochemical disciplines will help to unravel one of the mysteries in biology of the mechanisms driving self-organized pattern formation in development.

\section{Material and Methods}

\section{Definition of the model domain}

The cell bilayer is at any time $t$ approximated by a closed $2 \mathrm{D}$ surface ellipsoid $\Gamma(t)$, embedded in 3D space. The evolution of $\Gamma(t)$ is given by a diffeomorphic time-dependent representation $\vec{X}$, parameterized over the unit sphere $S^{2} \subset \mathbb{R}^{3}$. Thus, $\Gamma(t)$ is the image of $\vec{X}(\cdot, t)$ with $\vec{X}(\vec{s}, t): S^{2} \times[0, T] \rightarrow \mathbb{R}^{3}$ for a $T \in \mathbb{R}_{>0}$. Local concentrations of different gene products at time $t$ are given by a set of continuous functions $\Phi_{i}, i=1, \ldots, n$, on the deforming 


\begin{tabular}{|c|c|}
\hline variable name & explanation \\
\hline$\beta \_c a t$ & nuclear $\beta$-catenin/TcF \\
\hline$\beta_{-} c a t_{a n t}$ & $\beta \_c a t$ antagonist (presumably linked to Dickkopf1/2/4-C $[2,63$ or HyNkd) \\
\hline$W n t 3$ & HyWnt3 (possibly also involving HyWnt9/10c [51]) \\
\hline$W n t 3_{\text {ant }}$ & HyWnt3 antagonist (related to Sp5 [101], HmTSP [53], or Notum signaling) \\
\hline Head & head-related factors downstream of HyWnt3 (e.g., multiple Wnts [51]) \\
\hline$S D$ & Soure density (long-term storage of the head forming potential) \\
\hline Tent & $\begin{array}{l}\text { tentacle activator (may involve HyAlx } 86, \text { HyWnt8 and HyWnt5 } 76 \text { or } \\
\text { BMB5-8b } \sqrt{78} \text { ) }\end{array}$ \\
\hline Tent $t_{\text {ant }}$ & tentacle activator antagonist (unknown) \\
\hline
\end{tabular}

Table 1. Model variables and their biological interpretation.

tissue surface $\Gamma(t)$, defined as gene product concentrations per cell volume, $\Phi_{i}(t): \Gamma(t) \rightarrow \mathbb{R}_{\geq 0}$. In order to achieve a consistent formulation with chemical processes being defined on $S^{2}$ rather than on $\Gamma$, we redefine $\Phi_{i}$ accordingly. This can be done by using the fact that we can identify material points $\vec{X}(\vec{s}, t)$ on $\Gamma(t)$ with $\vec{s} \in S^{2}$, since $\vec{X}$ is smooth and bijective. Thus, for each $\vec{s} \in S^{2}, t \in[0, T]$, we define functions $\Phi_{i}: S^{2} \times[0, T] \rightarrow \mathbb{R}_{\geq 0}$ by $\Phi_{i}(\vec{s}, t)=\Phi_{i}(\vec{X}(\vec{s}, t))$.

\section{Molecular interactions}

In this model we consider 8 different molecular/chemical components $\Phi_{i}$, denoted by $\beta_{-}$cat, $\beta_{-} c a t_{a n t}, W n t 3$, $W n t 3_{a n t}$, Head, SD, Tent and Tent ${ }_{a n t}$. For an overview see Table 1 Here, $\beta \_c a t$ and $\beta \_c a t$ ant represent the activator and the inhibitor associated with the body-axis patterning system involving nuclear $\beta$-catenin/Tcf. Wnt 3 and $W n t 3_{a n t}$ are the activator and the inhibitor of the HyWnt3 organizer pattern formation system. Head is one of the several head-specific gene products downstream of the organizer (such as one of the multiple head-specific Wnts (76) $) S D$ denotes the source density, and Tent and Tent $t_{\text {ant }}$ describe activator respectively inhibitor of the tentacle system. The PDE system describing interactions among these component is given in Eq. (1)-(8), where $\Delta^{\Gamma}($.$) denotes surface Laplace (Laplace-Beltrami-) operator, and d_{t}$ stands for time-derivative.

More specifically, formulation of Eq. (1)-(2) describing the body-axis pattern formation system, Eq. (3)-(4) describing the organizer pattern formation system, and Eq. (5) the equation for Head. The tentacle system given by Eq. (6)-(7) and Eq. (8) for the source density are adopted from 61 63. For the sake of simplicity, we model the pattern formation system of $\beta$-catenin/Tcf using a system of reaction-diffusion equations, although $\beta$-catenin is a non-diffusive molecule localized in cells. The diffusion-based model is an abstract representation of a more complex pattern formation model in which the effective short-range cell-to-cell communication may be realized through interactions with Wnt signaling [3. A mechanism of pattern formation exhibited by components of intracellular signaling that are coupled to a single diffusive component have been demonstrated in a series of mathematical works 37,58. The desired pattern formation mechanism can be also realized by an interplay of $\beta$-catenin with mechanical cues. Such formation of morphogen patterns without any lateral chemical diffusion has recently been demonstrated in simulation studies based on a mechano-chemical model [16]. Having in mind several possible molecular mechanisms that may explain formation of the $\beta$-catenin/Tcf patterns, we formulate the current model in terms of a reduced mathematical metaphor of such mechanism. Similar modeling strategy was applied in the seminal works of Hans Meinhardt 61.63.

The extension of our model compared to previous models includes the separate activator-inhibitor system for the HyWnt3 organizer system an the additional variable Head that represents the head-specific molecules expressed downstream of the organizer in order to fine-scale the pattern the Hydra head region (e.g., multiple Wnts [51]). The activator-inhibitor system for HyWnt3 is strictly related to the tentacle system, i.e., a smallscale pattern formation system with a saturation of its own expression. The motivation for this is that (transient) HyWnt3 spots after ALP treatment show a comparable size and spacing compared to the ectopic tentacles (Fig. 1 b-c). Production terms in the HyWnt3 pattern formation system are furthermore assumed to additionally 
require $\beta$-catenin/Tcf as motivated within the Results and Discussion section. HyWnt3 again activates headspecific molecules $(\mathrm{Head})-$ but only above a certain threshold thresh $=5.0$. We introduced this threshold to account for the assumption that head construction only starts if the organizer is well established. Head again is assumed to negatively influence the tentacle system; this negative influence of the Hydra hypostomal region on the tentacle system has been demonstrated in different experiments $78,86,94$.

We want to point out that most of the various parameters appearing in Eq. (1-8) are not critical for the qualitative simulation results as presented within this study. In particular, most of them control specific properties of one of the three considered de novo pattern formation systems, such as the spatial scaling in general, the spacing between appearing maxima, or the required condition to start the de novo patterning process. Most of these parameter have been adopted from Ref. 61,63 and are neither in the focus of the current study, nor do they critically influence our main results, the latter concerning the interactions of the different patter formation systems in Hydra rather than details or the de novo pattern formation systems itself.

$$
\begin{aligned}
& d_{t} \beta_{-} c a t=\quad a_{1} \Delta^{\Gamma} \beta_{-} c a t+b_{1} \cdot S D \cdot \frac{0.05+\beta_{c a t}^{2}}{\beta_{-} c a t_{a n t}}-d_{1} \cdot \beta_{-} c a t \\
& d_{t} \beta_{-} c a t_{a n t}=a_{2} \Delta^{\Gamma} \beta_{-} c a t_{a n t}+b_{2} \cdot S D \cdot \beta_{c a t}^{2}-d_{2} \cdot \beta_{-} c a t_{a n t} \\
& d_{t} W n t 3=\quad a_{3} \Delta^{\Gamma} W n t 3+b_{3} \cdot \beta_{-} c a t \cdot \frac{0.005+W n t 3^{2}}{W n t 3_{a n t} \cdot\left(1.0+c_{3} \cdot W n t 3^{2}\right)} \\
& -d_{3} \cdot\left(1.0+e_{3} \cdot H A S\right) \cdot W n t 3 \\
& d_{t} W n t 3_{a n t}=\quad a_{4} \Delta^{\Gamma} W n t 3_{a n t}+b_{4} \cdot \beta_{-} c a t \cdot \frac{0.005+W n t 3^{2}}{1.0+c_{4} \cdot W n t 3^{2}}+0.06 \\
& -d_{4} \cdot W n t 3_{a n t} \\
& d_{t} H e a d=\quad a_{5} \Delta^{\Gamma} H e a d-d_{5} H e a d+\left(b_{5} \text { Wnt3 }\right) \mid \\
& d_{t} \text { Tent }=\quad a_{6} \Delta^{\Gamma} \text { Tent }+\frac{b_{6} \cdot S D \cdot\left(0.005+\text { Tent }^{2}\right)}{\text { Tent }_{\text {ant }} \cdot\left(1+c_{6} \cdot \text { Tent }^{2}\right) \cdot\left(1+e_{6} \cdot \text { Head }\right)}-d_{6} \cdot \text { Tent } \\
& d_{t} \text { Tent }_{\text {ant }}=\quad a_{7} \Delta^{\Gamma} \text { Tent }_{\text {ant }}+\frac{b_{7} \cdot S D \cdot\left(0.005+\text { Tent }^{2}\right)}{\left(1+c_{7} \cdot \text { Tent }^{2}\right) \cdot\left(1+e_{7} \cdot \text { Head }\right)}+0.014-d_{7} \cdot \text { Tent }_{\text {ant }} \\
& d_{t} S D=a_{8} \Delta^{\Gamma} S D+b_{8} \cdot \beta_{-} c a t+10^{-4}-d_{8} S D .
\end{aligned}
$$

\section{Tissue mechanics}

The chemical/molecular equations Eq. (1)-(8) have been augmented by a set of equations representing the deforming tissue surface. In particular, we treat the tissue as purely elastic, and elastic tissue deformations are based on minimization of the Helfrich free energy [39] which is given by

$$
\mathcal{F}_{\text {bend }}=\int_{\Gamma} \kappa\left(H-H_{0}\left(\beta_{-} c a t, T e n t\right)\right)^{2} d \vec{S}
$$

Here, $H$ is the mean curvature, $\kappa$ the bending rigidity, and $H_{0}$ the spontaneous curvature 66, 68. In particular, $H_{0}$ represents the locally preferred tissue curvature, which again may depend on local morphogen concentrations. Here, we assume $H_{0}\left(\beta_{\_} c a t_{a n t}\right.$, Tent $)=0.5 \cdot \beta_{-} c a t_{a n t}+15$. Tent, based on the observation that local tissue evaginations can be observed during both - budding and tentacle formation [1 76]. Local area-conserving evolution of the deforming Hydra tissue is finally given by the $L^{2}$-gradient flow of the total energy; further corresponding details are given in Ref. 68.

\section{Simulation method}

For simulations of the model we used the finite element library Gascoigne [5], approximating the fourth order PDEs in a mixed formulation. For spatial discretization we used linear finite elements (including local mesh 
refinement in areas with strong local curvatures); for time discretization a semi-implicit Euler scheme (including an adaptive time step scheme). For further details of the computation scheme we refer to 66,68$]$.

\section{Parameters and initial conditions}

For simulations of the undisturbed system, most of the parameters have been adapted from Ref. 61, 63. In particular, for the unperturbed system we used: $a_{1}=9 \times 10^{-5}, b_{1}=d_{1}=3 \times 10^{-3}, a_{2}=1.1 \times 10^{-2}, b_{2}=$ $3 \times 10^{-3}, d_{2}=4 \times 10^{-3}, a_{3}=2.25 \times 10^{-5}, b_{3}=4.8 \times 10^{-2}, c_{3}=1.8 \times 10^{-3}, d_{3}=1.2 \times 10^{-2}, a_{4}=0.9 \times 10^{-3}, b_{4}=$ $0.72 \times 10^{-1}, c_{4}=1.8 \times 10^{-3}, d_{4}=1.8 \times 10^{-2}, a_{5}=5 \times 10^{-4}, d_{5}=1 \times 10^{-2}, b_{5}=1, a_{6}=7.5 \times 10^{-5}, b_{6}=$ $2 \times 10^{-2}, c_{6}=e_{6}=1 \times 10^{-1}, d_{6}=2 \times 10^{-2}, a_{7}=3 \times 10^{-3}, b_{7}=3 \times 10^{-2}, c_{7}=e_{7}=1 \times 10^{-1}, d_{7}=3 \times 10^{-2}, a_{8}=$ $1.1 \times 10^{-4}, b_{8}=d_{8}=1 \times 10^{-4}$. To approximate the Hydra shape, initial conditions for $X_{1}, X_{2}$ and $X_{3}$ have been parameterized over the closed $2 \mathrm{D}$ unit-sphere $S^{2}$ embedded in $3 \mathrm{D}$ space with $X_{1}(t=0) \equiv X_{2}(t=0) \equiv 0$ and $X_{3}(t=0)=4 \cdot s_{3}$, thus, leading to a stretch into the direction of $s_{3}$ (given that $s_{1}, s_{2}, s_{3}$ are Eulerian coordinates of the $S^{2}$-surface). For chemicals, we used a stochastic initial distribution based on the standard random generator provided by $\mathrm{C}++$. The only exception was the source density, which has been provided with an initial gradient, namely via $S D(t=0)=4.0 \cdot\left(\exp \left(s_{3}\right) / \exp (1)\right)$. Thus, in all simulations, chemical patterns developed based on stochastic initial conditions, only the geometric and chemical body axis gradient has been initially provided. If ALP treatment has been simulated, we changed the initial conditions for the source density adding an offset by $S D(t=0)=2.0+4.0 \cdot\left(\exp \left(s_{3}\right) / \exp (1)\right) . \mathrm{Sp} 5$-knockdown has been simulated increasing degradation of $W n t 3 \_a n t$ by multiplying $d_{4}$ by the factor 1.7 , overexpression of $\beta$-catenin/Tcf respectively Wnt 3 has been realized adding the constant $c=0.003$ to the right-hand side of the corresponding equation.

\section{Acknowledgements}

This work was supported by the German Science Foundation in the framework of SFB1324/B06 to A.M-C. and SFB1324/A05 to T.W.H and through the Heidelberg STRUCTURES Excellence Cluster (EXC-2181/1 390900948). We thank Yukio Nakamura for the preparation of the actin::HyWnt3 pBSSA-AR vector and initial transgenic Hydra vulgaris AEP strains (DFG-FOR 942; T.W.H)

\section{References}

1. R. Aufschnaiter, R. Wedlich-Söldner, X. Zhang, and B. Hobmayer, Apical and basal epitheliomuscular F-actin dynamics during bud evagination., Biol. Open, 6 (2017), pp. 1137-48.

2. R. Augustin, A. Franke, K. Khalturin, R. Kiko, S. Siebert, G. Hemmrich, and T. C. G. Bosch, Dickkopf related genes are components of the positional value gradient in Hydra., Dev. Biol., 296 (2006), pp. $62-70$.

3. N. BARKer, The canonical Wnt/beta-catenin signalling pathway., Mol. Biol., 468 (2008), pp. 5-15.

4. L. Beccari, N. Moris, M. Girgin, D. A. Turner, P. Baillie-Johnson, A.-C. Cossy, M. P. Lutolf, D. Duboule, AND A. M. ARIAs, Multi-axial self-organization properties of mouse embryonic stem cells into gastruloids., Nature, 562 (2018), pp. 272-276.

5. R. Becker, M. Brafek, T. Dunne, D. Meidner, T. Richter, And B. Vexler, Gascoigne 3D- a finite element toolbox (http://www.gascoigne.uni-hd.de). 2005.

6. S. Berking, A model for budding in hydra: pattern formation in concentric rings, J. Theor. Biol., 222 (2003), pp. 37-52.

7. H. Bode, Axis formation in Hydra., Annu Rev Genet, 45 (2011), pp. 105-17.

8. H. R. Bode, Head regeneration in Hydra, Dev. Dyn., 226 (2003), pp. 225-36.

9. H. R. Bode, Axial patterning in Hydra., CSH Perspect. Biol., 1 (2009), p. a000463.

10. H. R. Bode, The head organizer in Hydra., Int. J. Dev. Biol., 56 (2012), pp. 473-8.

11. P. M. Bode AND H. R. Bode, Formation of pattern in regenerating tissue pieces of Hydra attenuata. I. Head-body proportion regulation., Dev. Biol., 78 (1980), pp. 484-96. 
12. T. C. G. Bosch, M. Adamska, R. Augustin, T. Domazet-Loso, S. Foret, S. Fraune, N. Funayama, J. Grasis, M. Hamada, M. Hatta, B. Hobmayer, K. Kawai, A. Klimovich, M. Manuel, C. Shinzato, U. Technau, S. Yum, And D. J. Miller, How do environmental factors influence life cycles and development? An experimental framework for early-diverging metazoans., BioEssays: news and reviews in molecular, cellular and developmental biology, 36 (2014), pp. 1185-94.

13. A. Böttger And M. Hassel, Hydra, a model system to trace the emergence of boundaries in developing eumetazoans., Int. J. Dev. Biol., 56 (2012), pp. 583-91.

14. E. BrAun AND K. Keren, Hydra regeneration: Closing the loop with mechanical processes in morphogenesis, BioEssays, 40 (2018), p. 1700204.

15. E. BRAUn AND H. ORI, Electric-induced reversal of morphogenesis in hydra regeneration, Bioph. J., 117 (2019), pp. 1514-1523.

16. F. Brinkmann, M. Mercker, T. Richter, And A. Marciniak-Czochra, Post-Turing tissue pattern formation: Advent of mechanochemistry., PLoS Comput. Biol., 14 (2018), p. e1006259.

17. M. Broun And H. R. Bode, Characterization of the head organizer in Hydra., Development, 129 (2002), pp. $875-84$.

18. M. Broun, L. Gee, B. Reinhardt, and H. R. Bode, Formation of the head organizer in Hydra involves the canonical Wnt pathway., Development, 132 (2005), pp. 2907-16.

19. M. Broun, S. Sokol, And H. R. Bode, Cngsc, a homologue of goosecoid, participates in the patterning of the head, and is expressed in the organizer region of Hydra., Development, 126 (1999), pp. 5245-54.

20. E. N. Browne, The production of new hydranths in Hydra by the insertion of small grafts, J. Exp. Zool., 7 (1909), pp. 1-23.

21. C. Cramer von LAue, Untersuchungen zur dualen Funktion von beta-Catenin im Wnt-Signalweg und der Cadherin-vermittelten Zelladhäsion bei Hydra, PhD thesis, Technische Universität Darmstadt, 2004.

22. W. Driever and C. Nüsslein-Volhard, A gradient of bicoid protein in drosophila embryos, Cell, 54 (1988), pp. 83-93.

23. A. C. Fröbius, G. Genikhovich, U. Kürn, F. Anton-Erxleben, and T. C. G. Bosch, Expression of developmental genes during early embryogenesis of Hydra., Dev. Genes Evol., 213 (2003), pp. $445-55$.

24. B. Galliot, Hydra, a fruitful model system for 270 years, Int. J. Dev. Biol., 56 (2012), pp. 411-23.

25. B. Galliot AND V. Schmid, Cnidarians as a model system for understanding evolution and regeneration., Int. J. Dev. Biol., 46 (2002), pp. 39-48.

26. A. Gamba, M. Nicodemi, J. Soriano, And A. Otт, Critical behavior and axis defining symmetry breaking in Hydra embryonic development., Phys .Rev. Lett., 108 (2012), p. 158103.

27. M. V. Gammons, M. Renko, J. E. Flack, J. Mieszczanek, And M. Bienz, Feedback control of Wnt signaling basedon ultrastable histidine cluster co-aggregation between Naked/NKD and Axin, eLife, 9 (2020), p. e59879.

28. L. Gee, J. Hartig, L. Law, J. Wittlieb, K. Khalturin, and T. Bosch, Beta-catenin plays a central role in setting up the head organiser in hydra, Dev. Biol., 340 (2010), pp. 226-24.

29. G. Genikhovich, U. Kürn, G. Hemmrich, And T. C. G. Bosch, Discovery of genes expressed in hydra embryogenesis., Dev. Biol., 289 (2006), pp. 466-81.

30. A. Gierer, The hydra model - a model for what?, Int. J. Dev. Biol., 56 (2012), pp. 437-45.

31. A. Gierer, S. Berking, H. Bode, C. David, K. Flick, G. Hansmann, H. Schaller, and E. TRenkneR, Regeneration of hydra from reaggregated cells, Nature New Biol., 239: 91 (1972), pp. 98101.

32. A. Gierer and H. Meinhardt, A theory of biological pattern formation., Kybernetik, 12 (1972), pp. 30-9.

33. C. GrimmelikhuiJzen And H. Schaller, Hydra as a model organism for the study of morphogenesis, TIBS, 4 (1979), pp. 265-7. 
34. C. Guder, I. Philipp, T. Lengfeld, H. Watanabe, B. Hobmayer, and T. W. Holstein, The Wnt code: cnidarians signal the way., Oncogene, 25 (2006), pp. 7450-60.

35. C. Guder, S. Pinho, T. G. Nacak, H. A. Schmidt, B. Hobmayer, C. Niehrs, and T. W. Holstein, An ancient Wnt-dickkopf antagonism in Hydra., Development, 133 (2006), pp. 901-11.

36. S. Gufler, B. Artes, H. Bielen, I. Krainer, M.-K. Eder, J. Falschlunger, A. Bollmann, T. Ostermann, T. Valovka, M. Hartl, K. Bister, U. Technau, and B. Hobmayer, $\beta$-Catenin acts in a position-independent regeneration response in the simple eumetazoan Hydra., Dev. Biol., 433 (2018), pp. 310-23.

37. S. HÄRTING AND A. MARCINIAK-CzOchrA, Spike patterns in a reactiondiffusion ode model with turing instability, Mathematical Methods in the Applied Science, 37 (2013), pp. 1377-1391.

38. M. HAssel AND A. Bieller, Stepwise transfer from high to low lithium concentrations increases the headforming potential in Hydra vulgaris and possibly activates the PI cycle., Dev. Biol., 177 (1996), pp. 439-48.

39. W. HelfRich, Elastic properties of lipid bilayers: theory and possible experiments., Z Naturforsch [C], 28 (1973), pp. 693-703.

40. B. Hobmayer, F. Rentzsch, K. Kuhn, C. M. Happel, C. C. von Laue, P. Snyder, U. Rothbächer, AND T. W. Holstein, Wnt signalling molecules act in axis formation in the diploblastic metazoan Hydra, Nature, 407 (2000), pp. 186-9.

41. E. Hobmayer, M. Hatta, R. Fischer, T. Fujisawa, T. W. Holstein, and T. Sugiyama, Identification of a Hydra homologue of the beta-catenin/plakoglobin/armadillo gene family., Gene, 172 (1996), pp. 155-9.

42. T. W. Holstein, The evolution of the Wnt pathway., CSH Perspect. Biol., 4 (2012), p. a007922.

43. T. W. Holstein, E. Hobmayer, And U. Technau, Cnidarians: an evolutionarily conserved model system for regeneration?, Dev. Dyn., 226 (2003), pp. 257-67.

44. R. Iachetta, A. Ambrosone, A. Klimovich, J. Wittlieb, G. Onorato, A. Candeo, C. D'Andrea, D. Intartaglia, N. Scotti, M. Blasio, A. Tino, A. Bassi, and C. Tortiglione, Real time dynamics of $\beta$-catenin expression during Hydra development, regeneration and wnt signalling activation., Int. J. Dev. Biol., 62 (2018), pp. 311-8.

45. V. Kadu, S. S Ghaskadbi, And S. Ghaskadbi, Induction of secondary axis in hydra revisited: New insights into pattern formation., Int. J. Mol. Cell Med., 1 (2012), pp. 11-20.

46. S. Kakugawa, P. F. Langton, M. Zebisch, S. Howell, T.-H. Chang, Y. Liu, T. Feizi, G. Bineva, N. O'Reilly, A. P. Snijders, E. Y. Jones, And J.-P. Vincent, Notum deacylates wnt proteins to suppress signalling activity, Nature, 519 (2015), pp. 187-192.

47. — Notum deacylates Wnt proteins to suppress signalling activity, Nature, 519 (2015), pp. $187-192$.

48. T. Käsbauer, P. Towb, O. Alexandrova, C. N. David, E. Dall'armi, A. Staudigl, B. Stiening, AND A. BöTtGer, The Notch signaling pathway in the cnidarian Hydra., Dev. Biol., 303 (2007), pp. 37690 .

49. Y. KomiYa And R. HABAs, Wnt signal transduction pathways., Organogenesis, 4 (2008), pp. 68-75.

50. L. Leclere, R. R. Copley, T. Momose, And E. Houliston, Hydrozoan insights in animal development and evolution, Curr. Opin. Genet. Dev., 39 (2016), pp. 157-67.

51. T. Lengfeld, H. Watanabe, O. Simakov, D. Lindgens, L. Gee, L. Law, H. A. Schmidt, S. Ozbek, H. Bode, AND T. W. HolsteIn, Multiple Wnts are involved in Hydra organizer formation and regeneration., Dev. Biol., 330 (2009), pp. 186-99.

52. A. Livshits, L. Shani-Zerbib, Y. Maroudas-Sacks, E. Braun, And K. Keren, Structural inheritance of the actin cytoskeletal organization determines the body axis in regenerating Hydra, Cell Rep., 18 (2017), pp. 1410-21.

53. M. Lommel, J. Strompen, A. L. Hellewell, G. P. Balasubramanian, E. D. Christofidou, A. R. Thomson, A. L. Boyle, D. N. Woolfson, K. Puglisi, M. Hartl, T. W. Holstein, J. C. Adams, AND S. ÖzBEK, Hydra mesoglea proteome identifies thrombospondin as a conserved component active in head organizer restriction., Sci. Rep., 8 (2018), p. 11753. 
54. M. Lommel, A. Tursch, L. R. Calvo, B. Trageser, and T. W. Holstein, Genetic knockdown and knockout approaches in hydra, www.biorxiv.org, (2018).

55. H. K. MaCWilliams, Numerical simulations of hydra head regeneration using a proportion-regulating version of the Gierer-Meinhardt model, J. Theor. Biol., 99 (1982), pp. 681-703.

56. H. K. MacWilliams, Hydra transplantation phenomena and the mechanism of hydra head regeneration. I. Properties of the head inhibition., Dev. Biol., 96 (1983), pp. 217-38.

57. — Hydra transplantation phenomena and the mechanism of hydra head regeneration. II. Properties of the head activation., Dev. Biol., 96 (1983), pp. 239-57.

58. A. MARCiniaK-Czochra, Receptor-based models with hysteresis for pattern formation in hydra, Math. Biosci., 199 (2006), pp. 97-119.

59. — Mathematics and Life Sciences, Germany: De Gruyter, 2012, ch. Reaction-diffusion models of pattern formation in developmental biology.

60. V. J. Martin, C. L. Littlefield, W. E. Archer, And H. R. Bode, Embryogenesis in hydra, Biol. Bull., 192 (1997), pp. 345-63.

61. H. Meinhardt, A model for pattern formation of hypostome, tentacles, and foot in hydra: how to form structures close to each other, how to form them at a distance, Dev. Biol., 157 (1993), pp. 321-33.

62. — - Models for the generation and interpretation of gradients., CSH Perspect. Biol., 1 (2009), p. a001362.

63. - Modeling pattern formation in hydra: A route to understanding essential steps in development., Int. J. Dev. Biol., 56 (2012), pp. 447-62.

64. H. MeInHARDT, Turing's theory of morphogenesis of 1952 and the subsequent discovery of the crucial role of local self-enhancement and long-range inhibition, Interface Focus, 2 (2012), pp. 407-16.

65. H. Meinhardt And A. Gierer, Pattern formation by local self-activation and lateral inhibition., Bioessays, 22 (2000), pp. 753-60.

66. M. Mercker, D. Hartmann, and A. Marciniak-Czochra, A mechanochemical model for embryonic pattern formation: coupling tissue mechanics and morphogen expression., PLoS One, 8 (2013), p. e82617.

67. M. Mercker, A. Köthe, And A. Marciniak-Czochra, Mechanochemical symmetry breaking in Hydra aggregates., Biophys. J., 108 (2015), pp. 2396-407.

68. M. Mercker, A. Marciniak-Czochra, T. Richter, and D. Hartmann, Modeling and computing of deformation dynamics of inhomogeneous biological surfaces, SIAM Journal on Applied Mathematics, 73(5) (2013), pp. 1768-1792.

69. W. A. MüLler, Pattern control in Hydra: basic experiments and concepts, in Experimental and Theoretical Advances in Biological Pattern Formation, H. Othmner, P. Maini, and J. Murray, eds., Boston: Springer, 1993, pp. 237-253.

70. S. Münder, S. Tischer, M. Grundhuber, N. Büchels, N. Bruckmeier, S. Eckert, C. A. Seefeldt, A. Prexl, T. Käsbauer, AND A. BötTger, Notch-signalling is required for head regeneration and tentacle patterning in Hydra, Dev. Biol., 383 (2013), pp. 146-57.

71. A. Nagafuchi And M. TAKeICHI, Transmembrane control of cadherin-mediated cell adhesion: a $94 \mathrm{kDa}$ protein functionally associated with a specific region of the cytoplasmic domain of E-cadherin, Cell Regul., 1 (1989), pp. 37-44.

72. Y. Nakamura, C. D. Tsiairis, S. ÖzBek, and T. W. Holstein, Autoregulatory and repressive inputs localize Hydra Wnt3 to the head organizer., Proc. Natl. Acad. Sci. U S A, 108 (2011), pp. 9137-42.

73. K. NoDA, Reconstitution of dissociated cells of Hydra, Zoology, 80 (1971), pp. 99-101.

74. J. J. Отto And R. D. CAmpbell, Budding in Hydra attenuata: bud stages and fate map, J. Exp. Zool. A Ecol. Genet. Physiol., 200 (1977), pp. 417-28.

75. C. P. PEtersen And P. W. Reddien, Wnt signaling and the polarity of the primary body axis, Cell, 139 (2009), pp. 1056-68. 
76. I. Philipp, R. Aufschnaiter, S. Özbek, S. Pontasch, M. Jenewein, H. Watanabe, F. Rentzsch, T. W. Holstein, AND B. Hobmayer, Wnt/beta-catenin and noncanonical Wnt signaling interact in tissue evagination in the simple eumetazoan Hydra, Proc. Natl. Acad. Sci. U S A, 106 (2009), pp. 4290-5.

77. P. C. Reddy, A. Gungi, S. Ubhe, S. J. Pradhan, A. Kolte, and S. Galande, Molecular signature of an ancient organizer regulated by Wnt/ $\beta$-catenin signalling during primary body axis patterning in Hydra, Commun. Biol., 2 (2019).

78. B. Reinhardt, M. Broun, I. L. Blitz, And H. R. Bode, HyBMP5-8b, a BMP5-8 orthologue, acts during axial patterning and tentacle formation in hydra., Dev. Biol., 267 (2004), pp. 43-59.

79. R. Rousset, J. A. Mack, K. A. Wharton, J. D. Axelrod, K. M. Cadigan, M. P. Fish, R. Nusse, AND M. P. ScOTT, Naked cuticle targets dishevelled to antagonize Wnt signal transduction, Genes Dev, 15 (2001), pp. 658-671.

80. T. S, F. K, A. S, AND G. B, Hydra, a powerful model for aging studies, Invertebrate Reproduction and Development, 59 (2005), pp. 11-16.

81. H. SANDER, Symmetry breaking in regenerating hydra: The role of fluctuations and cell mechanics, $\mathrm{PhD}$ thesis, Saarland University, 2016.

82. M. Sato, H. Tashiro, A. Oikawa, And Y. Sawada, Patterning in hydra cell aggregates without the sorting of cells from different axial origins., Dev. Biol., 151 (1992), pp. 111-6.

83. F. Schweisguth And F. Corson, Self-organization in pattern formation., Dev. Cell, 49 (2019), pp. 65977.

84. J. A. Sherratt, P. Maini, W. JäGer, And W. Müller, A receptor based model for pattern formation in Hydra, Forma, 10 (1995), pp. 77-95.

85. H. Shimizu, Transplantation analysis of developmental mechanisms in Hydra, Int. J. Dev. Biol., 56 (2012), pp. $463-72$.

86. K. M. Smith, L. Gee, And H. R. Bode, HyAlx, an aristaless-related gene, is involved in tentacle formation in hydra, Development, 127 (2000), pp. 4743-52.

87. J. Soriano, C. Colombo, And A. Otт, Hydra molecular network reaches criticality at the symmetrybreaking axis-defining moment., Phys Rev Lett, 97 (2006), p. 258102.

88. J. Soriano, S. Rüdiger, P. Pullarkat, And A. Отt, Mechanogenetic coupling of Hydra symmetry breaking and driven Turing instability model., Biophys. J., 96 (2009), pp. 1649-60.

89. R. E. Steele, Trembley's polyps go transgenic, Proc. Natl. Acad. Sci. U S A, 103 (2006), pp. 6415-6.

90. J. Taubenheim, D. Willoweit-Ohl, M. Knop, S. Franzenburg, T. C. Bosch, and S. Fraune, Bacteria-and temperature-regulated peptides modulate beta-catenin signaling in hydra, bioRxiv, doi (2019), p. https://doi.org/10.1101/7473.

91. U. Technau And H. R. Bode, HyBra1, a Brachyury homologue, acts during head formation in Hydra, Development, 126 (1999), pp. 999-1010.

92. U. Technau, C. Cramer von laue, F. Rentzsch, S. Luft, B. Hobmayer, H. R. Bode, and T. W. Holstein, Parameters of self-organization in Hydra aggregates., Proc. Natl. Acad. Sci. U S A, 97 (2000), pp. $12127-31$.

93. U. Technau And T. W. Holstein, Cell sorting during the regeneration of Hydra from reaggregated cells, Dev. Biol., 151 (1992), pp. 117-27.

94. _ Head formation in Hydra is different at apical and basal levels, Development, 121 (1995), pp. 127382.

95. A. TRembley, Mémoires pour servir à l'histoire d'un genre de polypes d'eau douce, à bras en forme de cornes, vol. 1, Chez Jean \& Herman Verbeek, 1744.

96. V. Trivedi, T. Fulton, A. Attardi, K. Anlas, C. Dingare, A. Martinez-Arias, and B. StevenTON, Self-organised symmetry breaking in zebrafish reveals feedback from morphogenesis to pattern formation, BioRxiv, (2019), p. 769257. 
97. A. M. Turing, The chemical basis of morphogenesis., Phil. Trans. R. Soc. Lond. B, 237 (1953), pp. 37-72.

98. D. A. Turner, P. Baillie-Johnson, And A. Martinez Arias, Organoids and the genetically encoded self-assembly of embryonic stem cells., BioEssays, 38 (2016), pp. 181-91.

99. D. A. Turner, M. Girgin, L. Alonso-Crisostomo, V. Trivedi, P. Baillie-Johnson, C. R. Glodowski, P. C. Hayward, J. Collignon, C. Gustavsen, P. Serup, et al., Anteroposterior polarity and elongation in the absence of extra-embryonic tissues and of spatially localised signalling in gastruloids: mammalian embryonic organoids, Development, 144 (2017), pp. 3894-3906.

100. M. Veschgini, H. O. Petersen, W. Abuillan, F. F. Rossetti, S. Özbek, M. Burghammer, T. W. Holstein, AND M. TANAKA, Spatio-temporal elasticity patterns in extracellular matrix during hydra morphogenesis, bioRxiv, doi (2017), p. https://doi.org/10.1101/214718.

101. M. C. Vogg, L. Beccari, L. Iglesias Oll. Rampon, S. Vriz, C. Perruchoud, Y. Wenger, and B. Galliot, An evolutionarily-conserved Wnt3/ $\beta$-catenin/Sp 5 feedback loop restricts head organizer activity in Hydra, Nat. Commun., 10 (2019), p. 312.

102. M. C. VogG, B. Galliot, And C. D. Tsiairis, Model systems for regeneration: Hydra, Development, 146 (2019), p. https://doi.org/10.1242/dev.177212.

103. A. WAGner, Distributed robustness versus redundancy as causes of mutational robustness, Bioessays, 27 (2005), pp. 176-88.

104. H. Watanabe, H. A. Schmidt, A. Kuhn, S. K. Höger, Y. Kocagöz, N. Laumann-Lipp, S. Özbek, And T. W. Holstein, Nodal signalling determines biradial asymmetry in hydra, Nature, 515 (2014), pp. $112-5$.

105. S. WERnER, H. T.-K. Vu, AND J. C. RINK, Self-organization in development, regeneration and organoids, Curr. Opin. Cell Biol., 44 (2017), pp. 102-9.

106. K. A. Wharton, G. Zimmermann, R. Rousset, and M. P. Scott, Vertebrate proteins related to drosophila naked cuticle bind dishevelled and antagonize wnt signaling, Dev Biol., 234 (2001), pp. 93-106.

107. J. Wittlieb, K. Khalturin, J. U. Lohmann, F. Anton-Erxleben, And T. C. G. Bosch, Transgenic hydra allow in vivo tracking of individual stem cells during morphogenesis., Proceedings of the National Academy of Sciences of the United States of America, 103 (2006), pp. 6208-6211.

108. L. Wolpert, Positional information and the spatial pattern of cellular differentiation., J. Theor. Biol., 25 (1969), pp. 1-47.

109. L. Wolpert, M. R. Clarke, And A. Hornbruch, Positional signalling along Hydra., Nature, 239 (1972), pp. 101-5.

110. T. YAO, Studies on the organizer problem in Pelmatohydra oligactis: I. the induction potency of the implants and the nature of the induced hydranth, J. Exp. Biol., 21 (1945), pp. 147-50.

111. X. Zhang, J. G. Abreu, C. Yokota, B. T. MacDonald, S. Singh, K. L. A. Coburn, S.-M. Cheong, M. M. Zhang, Q.-Z. Ye, H. C. Hang, H. Steen, And X. He, Tiki1 is required for head formation via Wnt cleavage-oxidation and inactivation, Cell, 149 (2012), pp. 165-177.

112. B. Ziegler, I. Yiallouros, B. Trageser, S. Kumar, M. Mercker, S. Kling, M. Fath, U. Warnken, M. Schnölzer, T. W. Holstein, M. Hartl, A. Marciniak-Czochra, J. SteteFELD, W. STÖCKER, AND S. ÖzBeK, A Wnt-specific astacin proteinase controls head formation in Hydra, biorxiv.org, (2020). 